\title{
Groundwater saving and quality improvement by reducing water footprints of crops to benchmarks levels
}

\author{
Fatemeh Karandish $^{\mathrm{a}, *}$, Arjen.Y. Hoekstra ${ }^{\mathrm{b}, \mathrm{c}}$, Rick J. Hogeboom ${ }^{\mathrm{b}}$ \\ ${ }^{a}$ Water Engineering Department, University of Zabol, Zabol, Iran \\ ${ }^{\mathrm{b}}$ Twente Water Centre, University of Twente, P.O. Box 217, Enschede 7500AE, The Netherlands \\ ${ }^{\mathrm{c}}$ Institute of Water Policy, Lee Kuan Yew School of Public Policy, National University of Singapore, 259770, Singapore
}

\section{A R T I C L E I N F O}

\section{Keywords:}

Water footprint assessment

Groundwater scarcity

Groundwater quality

Nitrate pollution

Benchmarking

Water saving

Crop production

\begin{abstract}
A B S T R A C T
The formulation of water footprint (WF) benchmarks in crop production - i.e. identifying reference levels of reasonable amounts of water consumption and pollution per tonne of crop produced - has been suggested as a promising strategy to counter inefficient water use and pollution. The current study is the first to show how setting WF benchmarks may help alleviate groundwater scarcity and pollution, in a case study for Iran. We advance the field of WF assessment by developing WF benchmark levels for crop production, which we successively use to assess potential groundwater saving, quality improvement and economic water productivity gains. First, we calculate climate-specific WF benchmark levels for both total blue water footprints and nitrogen-related grey groundwater footprints for 26 crops, for all years in the period $1980-2010$, at $5 \times 5^{\prime}$ spatial resolution. Second, we estimate the water saving potential for total blue water resources and for groundwater resources specifically, as well as the grey groundwater footprint reduction potential. Finally, we compare mean economic water productivities of crop production in the past with productivities if WFs are reduced to benchmark levels. We find that groundwater comprises up to $83 \%$ of total blue water consumption of irrigated crops, with the highest share in arid areas and in cereals. Aquifers are under significant to severe stress, except in the dry sub-humid zone, where irrigation mainly relies on surface water. Reducing WFs of crops to 25th percentile benchmark levels can save $32 \%$ of groundwater compared to the reference year 2010, and lower the nitrogen-related grey groundwater footprint by $23 \%$. Moreover, it would increase average economic groundwater productivity in Iran by $20 \%$ for cereals, and 59\% for nuts. We conclude that reducing WFs to climate-specific benchmark levels in a water-stressed country is a promising way to alleviate overexploitation of aquifers and increase national food security.
\end{abstract}

\section{Introduction}

A promising strategy to save water and reduce water pollution in the agricultural sector is to formulate benchmark levels for water footprints of crop production (Zwart et al., 2010; Brauman et al., 2013; Hoekstra, 2013; Mekonnen and Hoekstra, 2014; Zhuo et al., 2016b; Chukalla et al., 2017). A water footprint refers to the volume of water that is consumed or polluted to produce a tonne of product. The blue surfacewater footprint (blue SWF) refers to the consumption of surface water, the blue groundwater footprint (blue GWF) to the consumption of groundwater, and the green WF to the consumption of rainwater. The grey surface-water footprint (grey SWF) and grey groundwater footprint (grey GWF) are measures of surface water and groundwater pollution, respectively (Hoekstra et al., 2011). The blue and green WF components together form the total consumptive WF, while the grey WF is also called the degradative WF. Benchmarking water productivity $\left(\mathrm{kg} / \mathrm{m}^{3}\right)$ or wa- ter footprints $\left(\mathrm{m}^{3} / \mathrm{kg}\right)$ implies defining what is a reasonable amount of water appropriation for the process at hand given environmental conditions and technical possibilities. Benchmarks may vary with environmental factors like climate and soil (Hoekstra, 2013; Hoekstra, 2014). Consumption beyond the benchmark level indicates inefficient resource use. Benchmarks can be formulated based on good or best available technologies and management practices (Chukalla et al., 2015, 2017, 2018) or they can be set by considering the spread of actual WFs in a certain region and taking the WF level that is not being exceeded by the best $10 \%, 20 \%$ or $25 \%$ of the total production in that area (Mekonnen and Hoekstra, 2014; Zhuo et al., 2016b).

Although still in its infancy, the idea of developing benchmark levels has been elaborated in a few previous studies. In a global assessment, Mekonnen and Hoekstra (2014) developed benchmark levels for consumptive and grey WFs for various crops through an analysis at a spatial resolution of $5 \times 5^{\prime}$ and found that WF benchmark levels may be lower in a temperate than in a tropical climate. They found that if all producers

\footnotetext{
* Corresponding author.

E-mail address: f.karandish@uoz.ac.ir (F. Karandish).
} 
globally would achieve a consumptive WF similar to or lower than that of the best $25 \%$ of production, global blue water savings would sum up to $40 \%$ of the total water consumption in crop production. If grey WFs in crop production are reduced, worldwide, to the level of the best $25 \%$ of current global production, water pollution would be reduced by $54 \%$. Chukalla et al., $(2015,2017)$ studied the reduction potential of blue and green WFs for cereals by developing benchmarks for different alternative irrigation techniques, irrigation strategies, and different alternative mulching practices. Their results demonstrate that integrating drip irrigation with deficit irrigation and synthetic mulching may cause a $29 \%$ reduction in consumptive WF compared to conventional farming practices. Zhuo et al., (2016b) carried out a study for consumptive WF benchmarks of wheat in China, addressing the important question of the need to differentiate benchmarks based on environmental factors. Considering rain-fed versus irrigated croplands, wet versus dry years, warm versus cold years, four different soil classes and two different climate zones, they concluded that it is justified to differentiate benchmarks based on climate zones.

None of the previous studies quantified the effect that setting benchmarks may have on alleviating scarcity or pollution levels for groundwater specifically, which was not possible because none of them differentiated blue WFs into blue SWFs and blue GWFs. In addition, the economic benefits associated with more efficient water consumption due to benchmarking have not been quantified before. The current study aims to advance the field of water footprint assessment by (1) developing climate-specific benchmark levels for both blue and grey WFs, in a case study considering 26 crops in Iran over the period 1980-2010, (2) estimating water saving and water pollution reduction potential for Iran's groundwater resources, and (3) comparing the economic water productivities of actual crop production with productivities if WFs are reduced to benchmark levels. This comprehensive aim provides a much-needed wider perspective on inefficient water use in crop production in Iran in particular, and on the strategy of benchmarking WFs in general. Iran has been chosen as an exemplary case of heavy reliance on groundwater resources, a high degree of aquifer overexploitation, and much room for more efficient water use.

\section{Methods and data}

\subsection{Case study}

Iran spans an area of $1,640,195 \mathrm{~km}^{2}$ and is divided into 30 provinces (Fig. 1a). The long-term national averages of minimum ( $\mathrm{T}_{\min }$ ) and maximum $\left(\mathrm{T}_{\max }\right)$ temperatures are $12{ }^{\circ} \mathrm{C}$ and $25{ }^{\circ} \mathrm{C}$, respectively. The annual average precipitation is $244 \mathrm{~mm}$, but the south-eastern parts of the country (Sistan and Balouhestan provinces) receive much less precipitation $(104 \mathrm{~mm})$ and the northern parts (Gilan, Mazandaran and Golestan provinces) much more $(1033 \mathrm{~mm})$. Over the period 1980-2010, reference evapotranspiration varies in the range of $858-2374 \mathrm{~mm} \mathrm{y}^{-1}$ within the country, with the lowest and highest values in the humid and hyperarid zones, respectively (Karandish and Mousavi, 2016). Based on the De-Martonne classification method, Iran can be classified into five climate zones (Karandish and Mousavi, 2016): hyper-arid, semi-arid, arid, humid and dry sub-humid, with arid and semi-arid being the predominant classes (Fig. 1a). Despite their low freshwater availability, the arid and semi-arid zones are responsible for about $70 \%$ of the total irrigated crop production in the country (IMAJ, 2016).

Iran is suffering from unprecedented water scarcity of both surface water and groundwater resources. This scarcity has at least three main causes: rapid population growth combined with an uneven population distribution within the country; an inefficient agricultural sector; and mismanagement and thirst for development (Madani, 2014). Agriculture is by far the largest water user: $97 \%$ of the total net blue water abstraction in Iran relates to irrigated crop production (Hoekstra and Mekonnen, 2012). The impact of the inefficient agriculture becomes visible through the partial disappearance of lakes, like Urmia Lake
(Ghale et al., 2017), the drying up of rivers, like the Zayandehroud River (Madani, 2014), falling groundwater tables (Rahnema and Mirassi, 2014), pollution of water (Karandish et al., 2017a), and damage to ecosystems and local livelihoods (Madani, 2014). Moreover, inefficient water use leads to the loss of potential economic benefits that could be derived from increased yields.

Rapid depletion of the country's aquifers due to excessive groundwater abstractions to produce crops is arguably the most critical challenge of Iran's irrigated agriculture. Over $60 \%$ of the country's irrigation depends on non-renewable or renewable groundwater stocks (FAO, 2016). Iran's groundwater depletion, embedded in food production, was 28.4 billion $\mathrm{m}^{3} \mathrm{y}^{-1}$ in 2000 and increased to 33.3 billion $\mathrm{m}^{3} \mathrm{y}^{-1}$ in 2010 (Dalin et al., 2017). Water abstractions for irrigation have expanded beyond regional water availability levels. National statistics reveal that about 500,000 wells are operated by local farmers, without a license or permission for many of them (WRM, 2016). In addition to increased risks to national water security, serious environmental degradation is induced and environmental flow requirements are violated (Wada et al., 2012). Land subsidence and seawater intrusion are among the most substantial secondary environmental impacts of this unsustainable groundwater use (Bouwer, 1977; Konikow and Kendy, 2005).

The spatially uneven distribution of agricultural lands contributes to the mentioned challenges. Over $70 \%$ of the agricultural lands are located in arid and semi-arid zones. Here, groundwater contributes over $50 \%$ to total water use in agricultural food production (WRM, 2016). The staple crops required to feed Iran's population are sourced from provinces where groundwater is being highly depleted. Dalin et al. (2017) showed that Iran is in the top four countries of the world exposed to global food and water security risks due to producing and importing food irrigated from rapidly depleting aquifers.

\subsection{Green, blue and grey WFs of crop production}

The green water, total blue water, blue groundwater, blue surfacewater and grey groundwater footprints of crop production were calculated per crop at a spatial resolution of $5 \times 5^{\prime}$ for each growing season in the period 1980-2010, based on the accounting framework of Hoekstra et al. (2011). The green and total blue WFs of a crop $\left(\mathrm{m}^{3} \mathrm{t}^{-1}\right)$ were calculated as the actual seasonal green and blue evapotranspiration (ET, $\mathrm{m}^{3} \mathrm{ha}^{-1}$ ) divided by the crop yield $\left(\mathrm{Y}, \mathrm{t} \mathrm{ha}^{-1}\right)$. ET and $\mathrm{Y}$ were simulated using FAO's crop water productivity model AquaCrop, using a daily time step (Hsiao et al., 2009; Raes et al., 2009; Steduto et al., 2009). The model was initialized through a 5-year rain-fed fallow land simulation prior to the planting date, in order to dampen out effects of beginning conditions on the soil moisture composition, as was proposed by Siebert and Döll (2010) and Zhuo et al. (2016a). The model evaluates a daily soil water balance of the root zone to calculate ET:

$S_{[t]}=S_{[t-1]}+P_{[t]}+I_{[t]}+C R_{[t]}-R O_{[t]}-E T_{[t]}-D P_{[t]}$.

in which $S_{[t]}$ and $S_{[t-1]}$ are the soil water content at the end of day $t$ and $\mathrm{t}-1$, respectively, $P_{[t]}$ the precipitation on day $\mathrm{t}, I_{[t]}$ the irrigation water applied, $C R_{[t]}$ the capillary rise from the groundwater, $R O_{[t]}$ the surface runoff, $E T_{[t]}$ the evapotranspiration, and $D P_{[t]}$ the deep percolation. All terms are in mm. Capillary rise is not considered here since most groundwater tables are assumed to be deeper than one meter below the rooting zone. The green and total blue water fractions of $R O$ were calculated each day based on the relative shares of $P$ and $I$ in a day in the sum of $P+I$. The fractions green and total blue water in the soil water content over time were calculated following Chukalla et al. (2015), Zhuo et al. (2016a) and Karandish and Hoekstra (2017). This method is based on the assumption that the green water content in the soil increases when rainfall infiltrates in the soil and that the total blue water content increases when precipitation infiltrates. The fractions green and total blue water in the total soil water content at the end of the previous day were used to calculate the green and total blue fractions in ET and $D P$ on day t. 




Fig. 1. Provinces, municipalities and climatic regions of Iran, with the dominant climatic condition per province.

The total blue WF in each location and year is made up of two components: a blue groundwater footprint (GWF) and a blue surface-water footprint (SWF). We distinguished these components based on data on the fractions groundwater and surface water in irrigation per municipality as provided by WRM (2016).

The grey WF is an indicator of appropriated pollution assimilation capacity. Following the Global Water Footprint Standard (Hoekstra et al., 2011), we calculated the grey groundwater footprint (in $\mathrm{m}^{3} \mathrm{t}^{-1}$ ) related to the application of nitrogen $(\mathrm{N}$ ) fertilizer as follows:

Grey $G W F=\frac{\alpha A R /\left(c_{\max }-c_{\text {nat }}\right)}{Y}$

where $A R$ is the $\mathrm{N}$ fertilizer application rate to the field $\left(\mathrm{kg} \mathrm{ha}^{-1} \mathrm{y}\right.$-, $\alpha$ the fraction of this leaching to the groundwater, $C_{\max }$ the maximum acceptable $\mathrm{N}$ concentration in the groundwater $\left(\mathrm{kg} \mathrm{m}^{-3}\right), C_{\text {nat }}$ the natural $\mathrm{N}$ concentration in the groundwater $\left(\mathrm{kg} \mathrm{m}^{-3}\right)$, and $\mathrm{Y}$ the crop yield $\mathrm{t}$ $\mathrm{ha}^{-1}$ ). The product $\alpha A R$ represents the $\mathrm{N}$ load to groundwater. Based on the suggested values by Franke et al. (2013), we assume $\alpha=0.1$. A maximum acceptable $\mathrm{N}$ concentration of $50 \mathrm{mg}$ nitrate $\mathrm{L}^{-1}$ (or $11.3 \mathrm{mg}$ $\mathrm{N} \mathrm{L}^{-1}$ ) is adopted, based on EU Nitrates Directive (Monteny, 2001). We did not consider grey WFs for surface water in this study.

\subsection{Blue and grey WF benchmark levels and potential blue and grey WF reduction}

Per crop, per climate zone and per year, we determined benchmark levels for the total blue WF and the grey GWF. Following Mekonnen and Hoekstra (2014) and Zhuo et al. (2016b), WF benchmark levels were determined by ranking the grid-level WF values from smallest to largest, and plotting these sorted footprints against the corresponding cumulative percentage of total crop production. A WF benchmark for a certain crop, climate zone and year is then set by taking the WF at a given percentile of production, e.g. the 10th, 20th or 25th percentile of production. The 10th percentile benchmark level thus refers to the WF of that is not exceeded by the best $10 \%$ of the total production volume (with 'best' referring to the crops coming from the places with smallest WFs). We did this for both total blue WFs and grey GWFs. Subsequently, we estimated water saving potential if WFs are reduced - both total blue WFs and grey GWFs - to these benchmark levels.

To estimate the potential reduction of groundwater scarcity, we first calculated groundwater scarcity per climate zone, by dividing blue groundwater footprints of the 26 crops considered in this study by groundwater availability for the reference year 2010 (Schyns et al., 2015; Schyns and Hoekstra, 2014). We took groundwater availability (recharge) data from WRM (2016). Subsequently, we computed groundwater scarcity for the scenarios in which, per crop and per climate zone, actual total blue WFs are reduced to the climate-specific benchmark levels set by the 10th, 20th and 25th production percentiles. Following Hoekstra et al. (2012) and Hoekstra and Mekonnen (2016), we classified scarcity into four groups: low $(<20 \%)$, moderate $(20 \%-30 \%)$, significant $(30 \%-40 \%)$ and severe $(>40 \%)$ scarcity. The difference between the reference year and reduced WF scenarios gives an indication of the potential reduction in groundwater scarcity per climate zone.

To estimate the grey GWF reduction potential, we first calculated the water pollution level per climate zone by dividing the total grey GWF by groundwater availability for the reference year 2010. Next, we calculated groundwater pollution levels for the scenarios in which, per crop and per climate zone, actual grey GWFs are reduced to the benchmark levels set by the 10th, 20th and 25th production percentiles. When the water pollution level equals 1 , the complete groundwater flow in the considered region is required to assimilate the load of pollutants (Hoekstra et al., 2011). The difference between the reference year and reduced WF scenarios gives an indication of the potential reduction in groundwater pollution.

\subsection{Economic water productivity}

Following Aldaya et al. (2010) and Hogeboom and Hoekstra (2017), mean economic water productivity (EWP, in $\$ \mathrm{~m}^{-3}$ ) was calculated, per crop class, per climate zone, and per year, by dividing the producer price $\left(\$\right.$ ton $\left.^{-1}\right)$ by the total consumptive (i.e. green plus blue) WF $\left(\mathrm{m}^{3} \operatorname{ton}^{-1}\right)$. 
Table 1

Overview of data sources.

\begin{tabular}{|c|c|c|c|c|}
\hline Input variable & Source & Spatial resolution* & Temporal resolution & Remarks \\
\hline Irrigated area & IMAJ (2016) & Municipal per crop & Annual 1980-2010 & $\begin{array}{l}\text { Crop-specific municipal level irrigated area were downscaled } \\
\text { to the } 5 \times 5^{\prime} \text { resolution based on spatial distributions of } \\
\text { crop-specific irrigated areas by Siebert et al., } 2013 \text {. }\end{array}$ \\
\hline $\begin{array}{l}\text { Irrigation water resources } \\
\quad \text { (ground and surface water) }\end{array}$ & WRM (2016) & Municipal & & $\begin{array}{l}\text { Crop-specific municipal level irrigated amounts and recharge } \\
\text { were downscaled to the } 5 \times 5^{\prime} \text { resolution based on spatial } \\
\text { distributions of irrigated areas by Siebert et al. } 2013\end{array}$ \\
\hline $\begin{array}{l}\text { Applied } \mathrm{N} \text { fertilizer in irrigated } \\
\text { areas }\end{array}$ & IMAJ (2016) & municipal & annually & $\begin{array}{l}\text { Spatial distribution of applied } \mathrm{N} \text { fertilizer within the irrigated } \\
\text { areas was derived based on the ratio of crop irrigated area } \\
\text { within in a } 5 \times 5^{\prime} \text { unit to the crop irrigated area in the } \\
\text { corresponding municipal unit as a whole }\end{array}$ \\
\hline $\begin{array}{l}\text { Weather data (Tmin, Tmax, RH, } \\
\text { WS, n)** }\end{array}$ & IRIMO (2016) & 52 synoptic stations & daily & $\begin{array}{l}\text { Weather stations are shown in Karandish and Hoekstra (2017). } \\
\text { Raster maps were resampled in GIS to the } 5 \times 5^{\prime} \text { spatial } \\
\text { resolution. }\end{array}$ \\
\hline $\begin{array}{l}\text { Soil data (i.e. texture data and } \\
\text { the total soil water holding } \\
\text { capacity) }\end{array}$ & Batjes (2012) & $5 \times 5^{\prime}$ resolution & & - \\
\hline $\begin{array}{l}\text { Soil hydraulic characteristics } \\
\text { (PWP, FC, TS, Ks) })^{* * * *}\end{array}$ & Steduto et al., 2009 & Not applicable & & $\begin{array}{l}\text { Raster maps at } 5 \times 5^{\prime} \text { resolution were prepared based on } 5 \times 5^{\prime} \\
\text { soil texture map }\end{array}$ \\
\hline Climatic zones & & $5 \times 5^{\prime}$ & & $\begin{array}{l}\text { Climatic zones were determined based on the method by } \\
\text { De-Martonne, based on weather data (see above, available at } \\
5 \times 5^{\prime} \text { resolution and upscaled to the provincial level) }\end{array}$ \\
\hline
\end{tabular}

Based on the 30-year time series of WFs (1980-2010), EWP was calculated for both the actual conditions and the scenarios in which the consumptive WFs are reduced to the climate-specific benchmark levels at the best $10 \%$, the best $20 \%$, or the best $25 \%$ of Iran's crop production. Using less surface water and groundwater, while maintaining production levels, increases the economic output per unit of water allocated to the purpose of crop growing. We estimate the increase in economic water productivity (EWP, $\$ \mathrm{~m}^{-3}$ ) if producers were to adhere to benchmark levels calculated earlier in this study.

\subsection{Data}

All required data had to be obtained per crop and per year for the study period $1980-2010$, at the $5 \times 5^{\prime \prime}$ resolution. An overview of the data sources used, including downscaling and resampling procedures applied in case of deviating resolutions, is given in Table 1 . While all analyses are done at the $5 \times 5^{\prime}$ grid level, results are aggregated to and shown at the climate zone level for clarity.

Daily weather data at $5 \times 5^{\prime}$ resolution were derived from observations at 52 weather stations (Karandish and Hoekstra, 2017) located in five climate zones (IRIMO, 2016). $\mathrm{ET}_{\mathrm{o}}$ was calculated based on the FAOPenman-Monteith equation (Allen et al., 1998). Soil texture data and the total soil water holding capacity were obtained from Batjes (2012). For hydraulic characteristics for each type of soil, the indicative values provided by AquaCrop were used. We considered 26 crops commonly grown in Iran, classified into eight crop categories based on the FAO classification (Allen et al., 1998): cereals (wheat; barley; rice), roots and tubers (potato), sugar crops (sugar beet; sugar cane), pulses (bean; pea; lentil), nuts (pistachio; walnuts; almond; hazelnut), oil crops (cottonseed; soybean; canola), vegetables (tomato; onion) and fruits (apple; banana; date; grape; and citrus fruits including lime, lemon, tangerine, orange and grapefruit). Wheat in Iran is all winter wheat. Agricultural data for the irrigated and rain-fed crops, including crop sowing area (ha), irrigated area (ha), crop planting and harvesting dates, crop yield $\left(\mathrm{kg} \mathrm{ha}^{-1}\right)$, and $\mathrm{N}$-application rates were collected per crop per province per year from Iran's Ministry of Agriculture Jihad (IMAJ, 2016). Data on the fractions groundwater versus surface water for irrigation at municipal level were obtained from WRM (2016). Data on Iran's international trade per crop $\left(\mathrm{t}^{-1}\right)$ were taken from FAO (2017). Data on annual crop prices were retrieved from FAO (2017).

\section{Results}

\subsection{Blue and grey WF benchmark levels}

Table S-1shows the total blue WF benchmarks of different crops, at different production percentiles for each climate zone. When we show, for example, that the 25th percentile of the total blue WF of wheat in the semi-arid zone is $1067 \mathrm{~m}^{3} \mathrm{t}^{-1}$, we mean that the best $25 \%$ of wheat production in this climate zone ('best' in terms of 'having the smallest total blue WFs') has a total blue WF of $1067 \mathrm{~m}^{3} \mathrm{t}^{-1}$ or less. Significant differences between the benchmarks for different climate zones can be observed. Regardless of crop type, total blue WF benchmarks for the hyper-arid, arid and semi-arid zones are higher than for the humid and dry sub-humid zones. Except for citrus and date, the highest total blue WF benchmark levels are observed in the hyper-arid zone, while the lowest occur in the humid zone. The higher total blue WF benchmarks in the drier (semi-arid, arid and hyper-arid) zones are caused by the relatively high $\mathrm{ET}_{0}$ and actual $\mathrm{ET}$ and greater fraction of total blue water in the total water consumption. The results confirm the findings from previous studies that the total blue WF of crops is negatively correlated with precipitation, and positively with $\mathrm{ET}_{0}$ (Zwart et al., 2010; Zhuo et al., 2014).

Table S-2 shows the grey GWF benchmarks of different crops at different production percentiles for each climate zone. The variation across climate zones is smaller than in the case of the total blue WF benchmarks, because grey GWF benchmarks don't relate to ET, but rather to fertilizer application rates and yields.

Since at the national scale wheat is responsible for a relatively high fraction of both total blue WF and grey GWF, we show the spatial distribution of total blue WFs and grey GWFs of wheat production for the year 2010 in Fig. 2. Within the drier regions, total blue WFs below the 25th percentile benchmark level were mostly located in Esfahan (arid), Tehran (arid), Yazd (hyper-arid), Chaharmahal (semi-arid) and Kermanshah (semi-arid) provinces. These provinces have a relatively high irrigation density. In the water abundant regions, WFs below the 25th percentile benchmark level are observed in Gilan province (humid zone), 
(a)

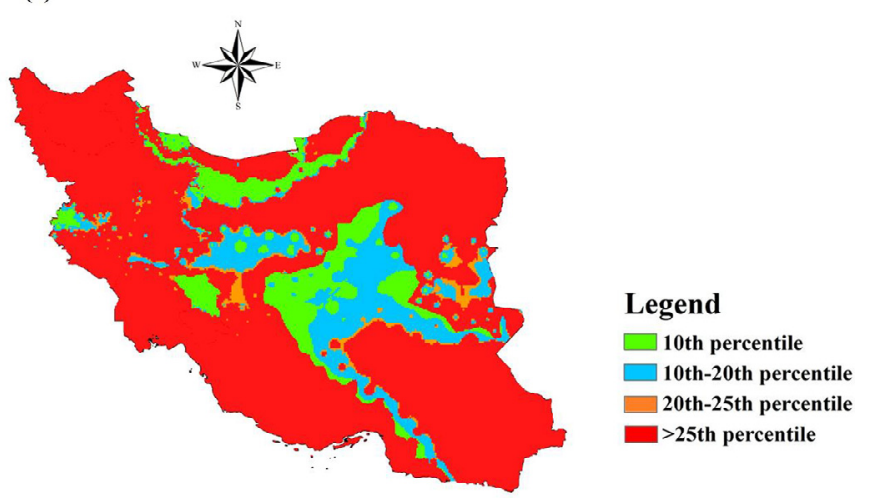

(b)

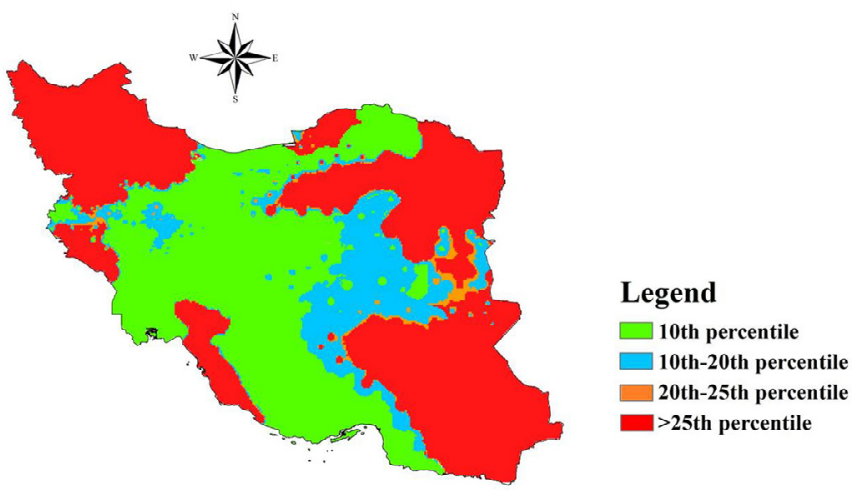

Fig. 2. Spatial distribution of the total blue water footprint(a) and grey groundwater footprint (b) of wheat In Iran, classified based on the WFs at the different production percentiles per climate zone. Spatial resolution: $5 \times 5^{\prime}$. Year: 2010 .

where $\mathrm{ET}_{0}$ is lower than in the other places. The national average total blue WF benchmark for wheat in Iran as a whole reflects the total blue WF benchmarks for arid and semi-arid zones, which can be explained by the fact that most of the crop production in Iran occurs in these zones.

Grey GWFs below the 25th percentile benchmark level are located in Esfahan (arid), Fars (arid), Qom (arid), Hormozgan (arid), Khuzestan (arid), North-Khorasan (arid), Yaz (hyper-arid), Chaharmahal (semiarid), Hamedan (semi-arid), Lorestan (semi-arid) and Markazi (semiarid) provinces and Mazandaran province (humid zone).

\subsection{Groundwater saving potential}

Fig. 3 shows the temporal variability of the groundwater saving that would be achieved if the total blue WFs of the various crops were reduced to the climate-specific total blue WF benchmark levels set by the 25 th percentiles of production, for each climate zone and within the whole country. The saving of groundwater specifically when reducing overall blue water consumption to the benchmark level depends on the groundwater fraction in the total blue water volume used. The potential groundwater saving when lowering total blue WFs down to the 25th percentile benchmark level were 3.2 billion $\mathrm{m}^{3} \mathrm{y}^{-1}$ in 1980 and 10.2 billion $\mathrm{m}^{3} \mathrm{y}^{-1}$ in 2010. Potential groundwater saving to groundwater consumption ratios varied between $30 \%$ and $34 \%$ during the period $1980-2010$. The highest groundwater savings over the period 1980-2010 were possible in the arid (1.7-5.4 billion $\mathrm{m}^{3} \mathrm{y}^{-1}$ ) and semi-arid (1.4-3.6 billion $\mathrm{m}^{3} \mathrm{y}^{-1}$ ) zones, where irrigated agriculture mainly relies on groundwater resources and where most of the crop production takes place.

The pronounced increase in groundwater saving potential over time is attributed to significantly higher groundwater consumption in 2010 relative to 1980 . This increase is caused by a rapid growth of area under irrigation in particularly the water-scarce arid and semi-arid regions of the country. Previous studies confirm such substantial increase in overall blue water consumption in irrigated agriculture in Iran over the period 1980-2010 (Karandish and Hoekstra, 2017).

Fig. 4 shows that there is an expressed difference between various crop classes in terms of the absolute groundwater saving potential upon lowering total blue WFs down to the 25th percentile benchmark level. The largest groundwater saving can be achieved in cereal production $\left(1.7-4.5\right.$ billion $\left.\mathrm{m}^{3} \mathrm{y}^{-1}\right)$, especially wheat, while roots and tubers $(0.04$ 0.16 billion $\mathrm{m}^{3} \mathrm{y}^{-1}$ ) show the lowest absolute potential. Saving potential across crop classes is - as expected - correlated with the area of irrigated land attributed to each class.

Table 2 shows groundwater scarcity caused by groundwater consumption for the reference year 2010. While groundwater resources are under severe stress in the hyper-arid, arid and semi-arid zones, the dry sub-humid zone experiences a low pressure on the renewable groundwater resources. This can be explained by the fact that irrigated agriculture in the latter climate zone mainly relies on surface water. Aquifers in the humid zone are significantly water stressed under current agricultural management practices. The main reason is that rice grown here requires large amounts of mostly groundwater (cf. Karandish et al., 2017a). As shown in Table 2, lower scarcity levels may be achieved when WFs are reduced to the benchmark levels in all climate zones. The exception is in the hyper-arid zone, where aquifers will remain under severe water stress in any scenario. At national level, a 32\% reduction in groundwater scarcity is possible compared to the reference year 2010 when reducing water consumption to the 25th percentile benchmark levels. Then still, Iran's aquifers will remain under significant water stress - especially in arid and hyper-arid zones - indicating that too much water is being used in total, even if the water would be used much more efficiently.

\subsection{Groundwater pollution reduction potential}

Iran's aquifers are mainly located in areas with intensive agriculture, and suffer from diffuse nitrate pollution from the excessive use of $\mathrm{N}$ fertilizers, particularly in cereal fields (Fig. 5). Intensive agriculture in predominantly arid and semi-arid zones results in the largest groundwater pollution by nitrate in these areas. Lowering grey GWFs down to climate-specific benchmark levels set by the 25th percentile of production will reduce the grey GWF of agricultural production by $23 \% \mathrm{com}$ pared to the actual grey GWF in 2010 (11\% in the dry sub-humid and $38 \%$ in the hyper-arid zone). In absolute sense, the biggest reduction in water pollution at national scale can be achieved in cereal production.

Table 3 shows the water pollution level of aquifers for each climate zone for the reference year 2010 and for the scenarios in which grey GWFs would be reduced to the benchmark levels set by the 25th, 20th and 10th production percentiles. The average water pollutant levels per climate zone remain smaller than 1 in the reference year, indicating that the waste assimilation capacity has not yet been fully reached. Nevertheless, nitrate pollution is severe in aquifers located within the semiarid and humid zones, where $50 \%$ and $70 \%$ of groundwater is required, respectively, to assimilate the pollutant load.

\subsection{Increasing economic water productivity}

Fig. 6 shows the economic water productivity $\left(\$ \mathrm{~m}^{-3}\right)$ for each crop class and climate zone, both mean EWP in 2010 and EWPs for the 10th, 20th and 25th production percentile in the same year. EWP of crops varied across the country following variations in both price and water consumption, with the largest absolute EWP values in the humid region. Fruits (1.6-3.2 $\left.\$ \mathrm{~m}^{-3}\right)$, vegetables $\left(0.9-1.8 \$ \mathrm{~m}^{-3}\right)$ and roots and fibres (1.3-1.7 $\$ \mathrm{~m}^{-3}$ ) generated the highest economic value per drop, while pulses and oil crops - the most water intensive crops - yielded the lowest EWP. In 2010, cereals had the largest share in national water consumption, but, for Iran as a whole, production yielded $62.3 \%, 32.2 \%$ and $26.3 \%$ less value per drop than production of fruits, vegetables and 
a) Groundwater saving for all crops

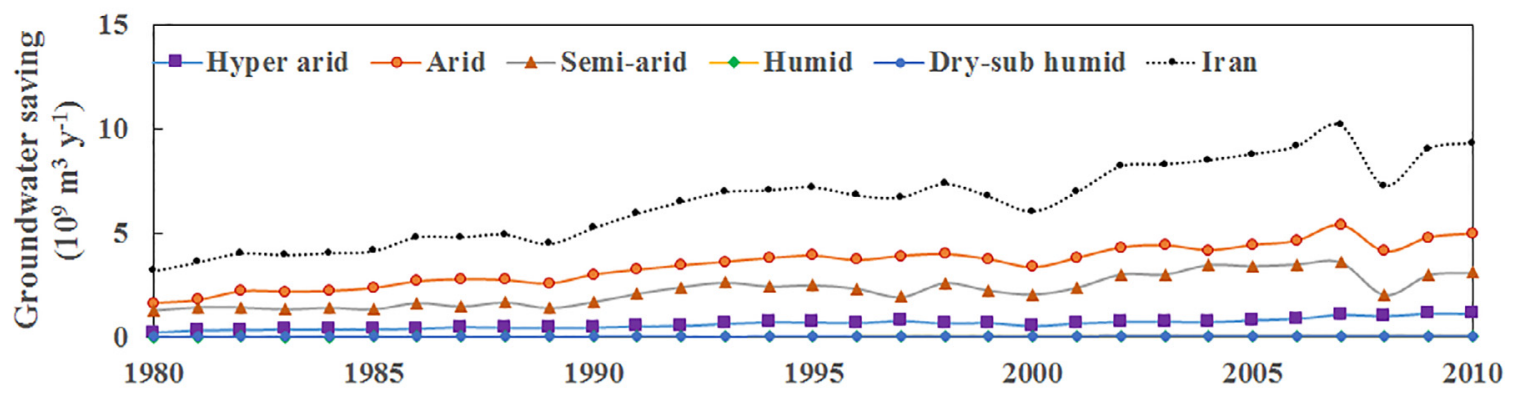

b) Groundwater pollution reduction for all crops

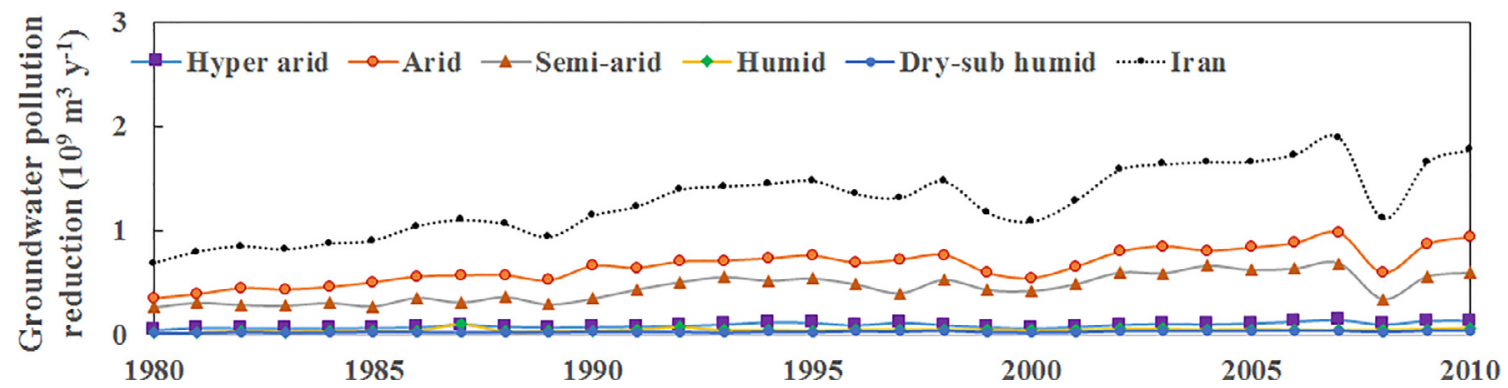

Fig. 3. Groundwater saving (blue groundwater footprint reduction) and groundwater pollution reduction (grey groundwater footprint reduction) for each climate zone and Iran as a whole over the period 1980-2010, if total blue WFs were lowered to 25th percentile benchmark levels.

Table 2

Groundwater scarcity as the ratio of blue groundwater footprint to groundwater availability (annual recharge), per climate zone, for the reference year 2010 and in case the total blue WFs in 2010 were lowered to different benchmark levels (pertaining to the 25th, 20th and 10th production percentiles).

\begin{tabular}{|c|c|c|c|c|c|}
\hline & Climate zone & $\begin{array}{l}\text { Blue groundwater } \\
\text { footprint } \\
\left(10^{9} \mathrm{~m}^{3} \mathrm{y}^{-1}\right)\end{array}$ & $\begin{array}{l}\text { Groundwater } \\
\text { availability } \\
\left(10^{9} \mathrm{~m}^{3} \mathrm{y}^{-1}\right)\end{array}$ & Ground water scarcity & Level of water scarcity \\
\hline \multirow[t]{6}{*}{ Reference year 2010} & Hyper-arid & 4.7 & 6.7 & 0.7 & Severe \\
\hline & Arid & 15.1 & 24.4 & 0.6 & Severe \\
\hline & Semi-arid & 9.1 & 15.2 & 0.6 & Severe \\
\hline & Humid & 0.4 & 1.0 & 0.4 & Significant \\
\hline & Dry sub-humid & 0.5 & 2.2 & 0.2 & Low \\
\hline & Iran & 29.8 & 49.5 & 0.6 & Severe \\
\hline \multirow[t]{6}{*}{ 25th percentile } & Hyper-arid & 3.6 & 6.7 & 0.5 & Severe \\
\hline & Arid & 10.1 & 24.4 & 0.4 & Significant \\
\hline & Semi-arid & 6.0 & 15.2 & 0.4 & Significant \\
\hline & Humid & 0.4 & 1.0 & 0.4 & Significant \\
\hline & Dry sub-humid & 0.4 & 2.2 & 0.2 & Low \\
\hline & Iran & 20.4 & 49.5 & 0.4 & Significant \\
\hline \multirow[t]{6}{*}{ 20th percentile } & Hyper-arid & 3.5 & 6.7 & 0.5 & Severe \\
\hline & Arid & 10.3 & 24.4 & 0.4 & Significant \\
\hline & Semi-arid & 5.6 & 15.2 & 0.4 & Significant \\
\hline & Humid & 0.3 & 1.0 & 0.3 & Moderate \\
\hline & Dry sub-humid & 0.4 & 2.2 & 0.2 & Low \\
\hline & Iran & 20.2 & 49.5 & 0.4 & Significant \\
\hline \multirow[t]{6}{*}{ 10th percentile } & Hyper-arid & 3.2 & 6.7 & 0.5 & Severe \\
\hline & Arid & 9.7 & 24.4 & 0.4 & Significant \\
\hline & Semi-arid & 4.8 & 15.2 & 0.3 & Moderate \\
\hline & Humid & 0.3 & 1.0 & 0.3 & Moderate \\
\hline & Dry sub-humid & 0.4 & 2.2 & 0.2 & Low \\
\hline & Iran & 18.4 & 49.5 & 0.4 & Significant \\
\hline
\end{tabular}

root and fibres, respectively, caused by their low yield and high water consumption. Reducing the WFs to 25th percentile benchmark levels improves farm economics, through increasing average EWP in Iran by $19.5 \%$ for cereals, $55.1 \%$ for vegetables, $25.2 \%$ for roots and fibres, $31.1 \%$ for pulses, $21.4 \%$ for sugar crops, $58.8 \%$ for nuts, $29.3 \%$ for oil crops, and $36.7 \%$ for fruits. The highest increases in EWP are generally found in the provinces located in the arid and semi-arid zones.

\section{Discussion}

This study into the development and application of WF benchmarks for crop production in Iran includes various limitations and uncertainties. First, we used the AquaCrop model to estimate ET and yield, using default parameters per crop. Calibration and validating model 
Table 3

Groundwater pollution level as the ratio of grey groundwater footprint to groundwater availability, per climate zone, for the reference year 2010 and in case the grey groundwater footprints in 2010 were lowered to different benchmark levels (pertaining to the 25th, 20th and 10th production percentiles).

\begin{tabular}{|c|c|c|c|c|}
\hline & Climate zone & $\begin{array}{l}\text { Grey groundwater } \\
\text { footprint } \\
\left(10^{9} \mathrm{~m}^{3} \mathrm{y}^{-1}\right)\end{array}$ & $\begin{array}{l}\text { Groundwater } \\
\text { availability } \\
\left(10^{9} \mathrm{~m}^{3} \mathrm{y}^{-1}\right)\end{array}$ & Water pollution leve \\
\hline \multirow[t]{6}{*}{ Reference year 2010} & Hyper-arid & 0.5 & 2.0 & 0.2 \\
\hline & Arid & 3.6 & 9.3 & 0.4 \\
\hline & Semi-arid & 2.8 & 6.1 & 0.5 \\
\hline & Humid & 0.4 & 0.6 & 0.7 \\
\hline & Dry sub-humid & 0.3 & 1.7 & 0.2 \\
\hline & Iran & 7.7 & 19.7 & 0.4 \\
\hline \multirow[t]{6}{*}{ 25th percentile } & Hyper-arid & 0.3 & 3.1 & 0.1 \\
\hline & Arid & 2.7 & 14.3 & 0.2 \\
\hline & Semi-arid & 2.2 & 9.2 & 0.2 \\
\hline & Humid & 0.4 & 0.6 & 0.6 \\
\hline & Dry sub-humid & 0.3 & 1.8 & 0.2 \\
\hline & Iran & 5.9 & 29.1 & 0.2 \\
\hline \multirow[t]{6}{*}{ 20th percentile } & Hyper-arid & 0.3 & 3.2 & 0.1 \\
\hline & Arid & 2.6 & 14.1 & 0.2 \\
\hline & Semi-arid & 2.2 & 9.6 & 0.2 \\
\hline & Humid & 0.4 & 0.7 & 0.6 \\
\hline & Dry sub-humid & 0.3 & 1.8 & 0.2 \\
\hline & Iran & 5.8 & 29.3 & 0.2 \\
\hline \multirow[t]{6}{*}{ 10th percentile } & Hyper-arid & 0.3 & 3.5 & 0.1 \\
\hline & Arid & 2.5 & 14.7 & 0.2 \\
\hline & Semi-arid & 2.1 & 10.4 & 0.2 \\
\hline & Humid & 0.3 & 0.7 & 0.5 \\
\hline & Dry sub-humid & 0.3 & 1.8 & 0.1 \\
\hline & Iran & 5.5 & 31.1 & 0.2 \\
\hline
\end{tabular}

parametrizations to the local context, based on local or field data, would improve trust in the outcomes (Karandish and Šimůnek, 2018).

The use of data sources of differing spatial scales can cause inconsistencies in the results. Most of the available data were reported at the municipal level and subsequently downscaled to a $5 \times 5^{\prime}$ resolution, thereby potentially affecting the results. A comparison with a previous study by Mekonnen and Hoekstra (2011) in Fig. 7 shows that our results differ in the range of $\pm 40 \%$ for total blue WFs, to $\pm 60 \%$ for grey WFs, which can be explained by differences in models and data sources used, but also by the input data resolution used. Most of our input data were reported at the municipal level, while Mekonnen and Hoekstra (2011) used predominantly national level data.

We determined the benchmark levels specifically for various climatic zones, rather than considering other environmental factors such as soil type and slope, following Zhuo et al. (2016). Including the effect of soils, slopes and other local environmental factors on ET and yields when formulating benchmarks could possibly refine the results of this study, but by taking benchmarks at the 25th percentile of best production was are at the conservative side when estimating potential water savings and pollution reduction.

In order to explore the sensitivity of our results, we carried out a sensitivity analysis for selected model parameters for a simulation for wheat. We analysed the most sensitive parameters according to Hui-Min et al. (2017). In their a global assessment for winter wheat, they found that eight parameters to be most sensitive: growing degree days from sowing to flowering (FLO), upper threshold of soil water depletion factor for canopy senescence (PSEN), total length of crop cycle in growing degree-days (MAT), crop coefficient when canopy is complete but prior to senescence (KCB), normalized water productivity (WP), harvest index (HI), maximum canopy cover in fraction soil cover (MCC), and growing degree day decrease in canopy cover (CDC). We assessed the relative change in model-simulated wheat yield and crop water consumption if each of the selected eight parameters were adjusted by $\pm 20 \%$ alone. Table 4 shows that the output parameters changed in the range of $-70 \%$ to $21 \%$ and $-16 \%$ to $3 \%$, respectively. Sensitivities varied per climatic region. Such adjustment in the selected eight parameters may consequently result in a $-17 \%$ to $178 \%$ change in the estimated groundwater saving and a $-17 \%$ to $219 \%$ change in the reduced grey GWF. Table 4 also shows that MAT is the most sensitive parameter, causing the largest relative change in crop yield and water consumption, and consequently in groundwater saving and grey GWF reduction.

Based on these limitations and uncertainties we consider the current study as explorative. Formulating WF reduction targets for crop production, as a general national policy, and to downscale targets per climate zone to specific targets at farm level still await practical implementation. The field is still in its infancy, with only a few earlier studies available for total blue WF benchmarks (Hoekstra, 2013; Mekonnen and Hoekstra, 2014; Chukalla et al., 2015, 2017; Zhuo et al., 2016b) or grey WF benchmarks (Mekonnen and Hoekstra, 2014; Chukalla et al., 2018). Further studies, using different models and remote sensing, and validating findings based on field data, will be necessary to assess uncertainties in more detail, and test the feasibility of lowering the WFs of crops to benchmark levels at large scale.

Regarding the results, we found that reducing WFs to benchmark levels has the largest water saving effect when applied for cereals, nuts and fruits and in the arid and semi-arid zones. A risk of water saving is that farmers increase their production volume once they require less water per unit of crop production, thereby undoing the original saving (Hoekstra, 2013). Besides, while an overall alleviation of groundwater scarcity may be achieved by reducing crop WFs to the benchmark levels, regional aquifers will still remain under severe stress, particularly in the hyper-arid zone. Hence, benchmarking WFs of crop needs to be integrated with the other possible groundwater management solutions to achieve sustainable agriculture.

Unsustainable groundwater consumption will limit future groundwater availability, thereby posing a serious threat to food security. Hence, new policies should aim at slowing down groundwater depletion to protect national food security. Given that under climate change irrigation 


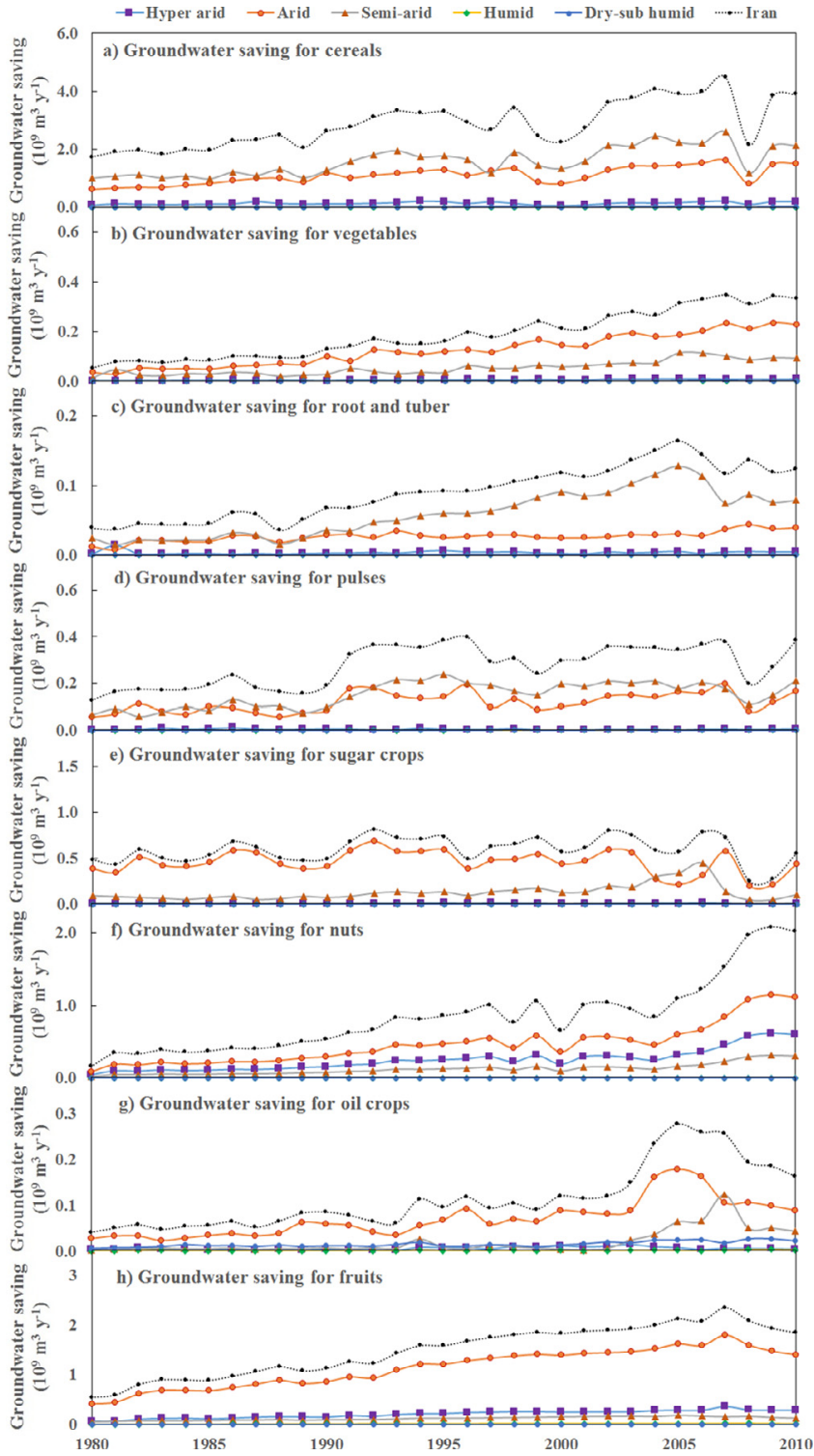

Fig. 4. Temporal variation of groundwater saving for various crop classes, for each climate zone and Iran as a whole over the period 1980-2010, if total blue WFs were lowered to 25 th percentile benchmark levels.

water requirements are expected to increase in Iran (Karandish et al., 2017b; Karandish and Mousavi, 2016), groundwater will be a more valuable resource still. Additionally, rain-fed agriculture is likely to experience increased periods of drought, as indicated by a significant increase in green water deficits under global warming in Iran (Karandish and Mnousavi, 2016). Under such circumstances, groundwater becomes a valuable supplemental water source in rain-fed cultivation, to secure adequate crop yields in the future.

Economic water productivity (EWP) is another factor that decision makers should take into consideration when allocating water resources (Mekonnen et al., 2012; Hoekstra, 2013; Schyns et al., 2015; Hogeboom and Hoekstra, 2017). Our results suggest that Iran's groundwater can be used more economically efficient if actual WFs of crops are lowered down to the climate-specific benchmark levels. The potential increase in productivity is higher in the arid than in the humid zone. While nuts potentially have the highest increase in value per drop when the consumptive WFs of crops are lowered down to benchmark levels, the highest national income increase in absolute terms $\left(\$ \mathrm{y}^{-1}\right)$ can be

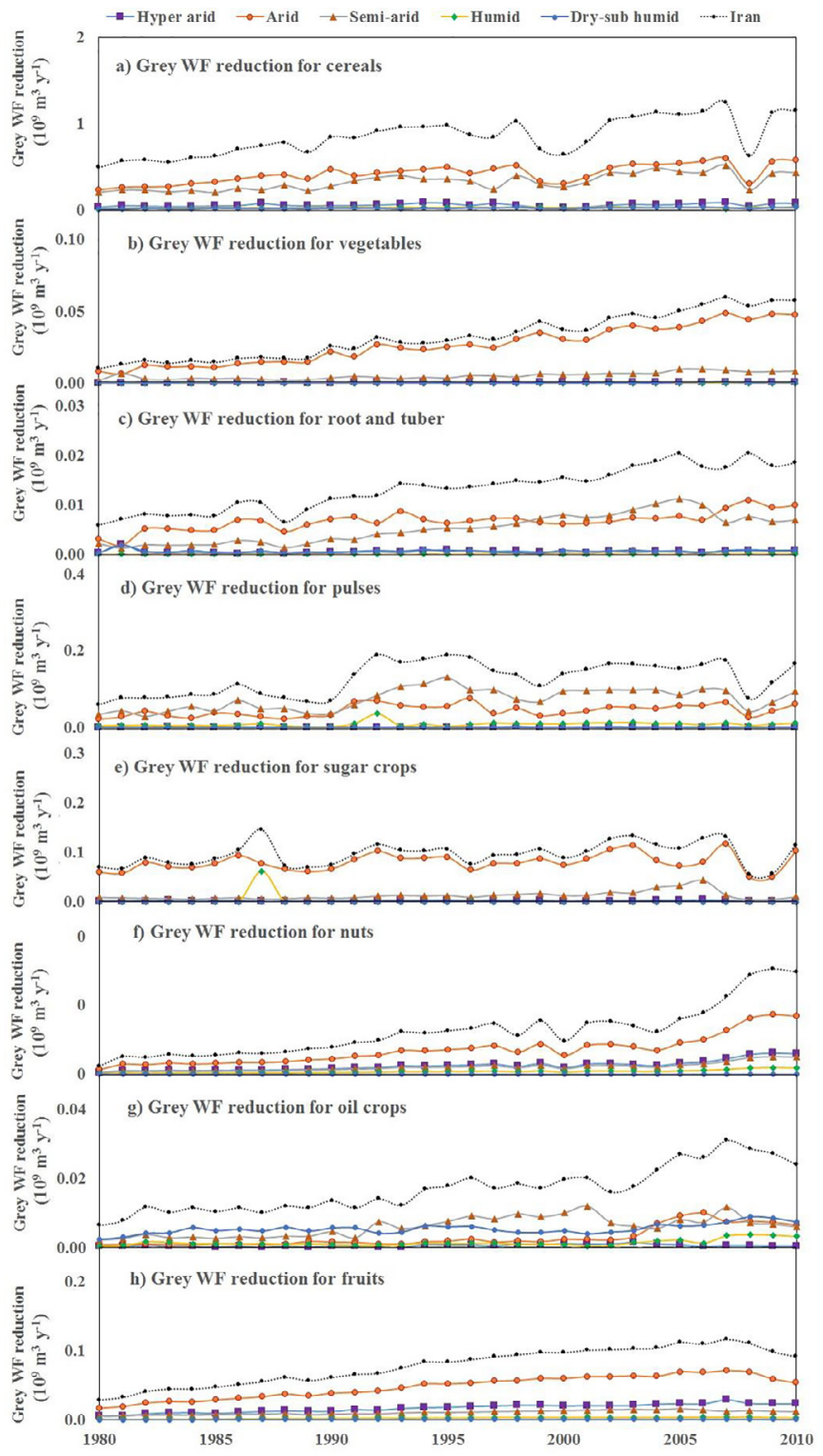

Fig. 5. Temporal variation of grey groundwater footprint reduction for various crop classes, for each climate zone and Iran as a whole over the period 1980 2010 , if actual grey groundwater footprints were lowered to 25th percentile benchmark levels.

achieved when efficiencies are improved in cereal production because of the volume of cereal production.

Marstone et al. (2015) proposed paying a premium on groundwaterirrigated crops, to be used to store groundwater for future use, a solution that may be considered as a payment for ecosystem services (Naeem et al., 2015) and may be well-received by policy makers (Qureshi et al., 2012). This would also provide a price signal of water scarcity to consumers. Any increase in the price of domestically produced crops, however, may lead consumers to buy imported food commodities at cheaper rates (Marstone et al., 2015). This would increase the dependency on other countries' water resources, thereby potentially posing another risk to food security. Another adaptation solution to reduce the pressure on aquifers is to reconsider which crops can best be grown where, based on water resources availability per climate zone, and the irrigation requirements and economic water productivity of different crops. 


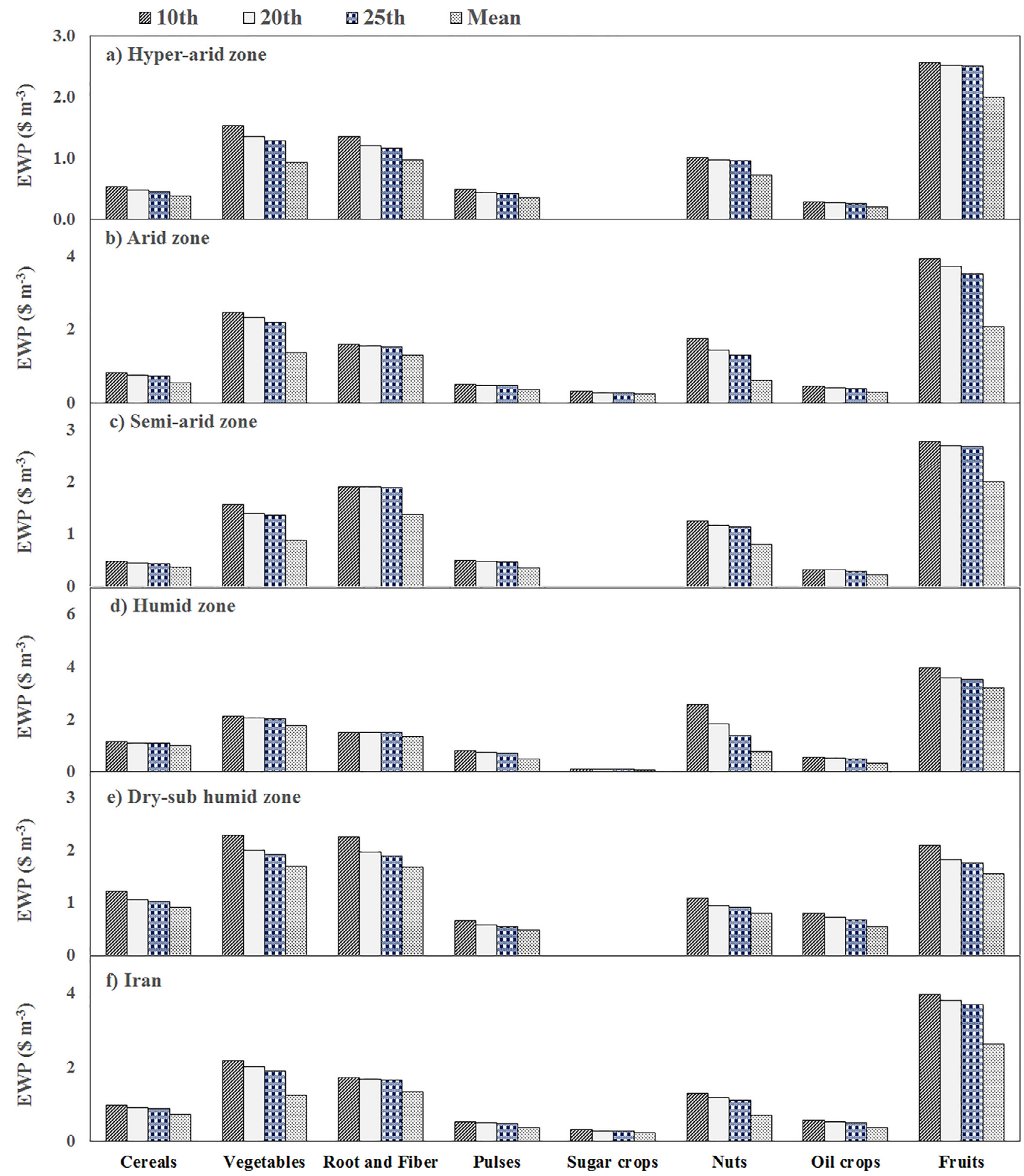

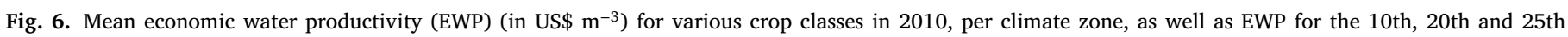
production percentile.

The current study has been able to quantify the effect of lowering water footprints to certain benchmark levels on alleviating groundwater scarcity and pollution. Besides, we quantified the economic benefits associated with more efficient water consumption due to benchmarking.
Our method is novel in a way that the benchmark levels for the total blue WFs are developed for different climatic regions, allowing spatially disaggregated quantification of potential water savings, thus better reflecting observed regional WF differences. Unlike previous studies that only 
Table 4

Relative change in AquaCrop-simulated yield and water consumption of wheat in response to a $\pm 20 \%$ change in sensitive crop parameters for different climatic regions, and the consequent change in groundwater saving and grey groundwater footprint reduction if total blue WFs are lowered to the benchmark levels.

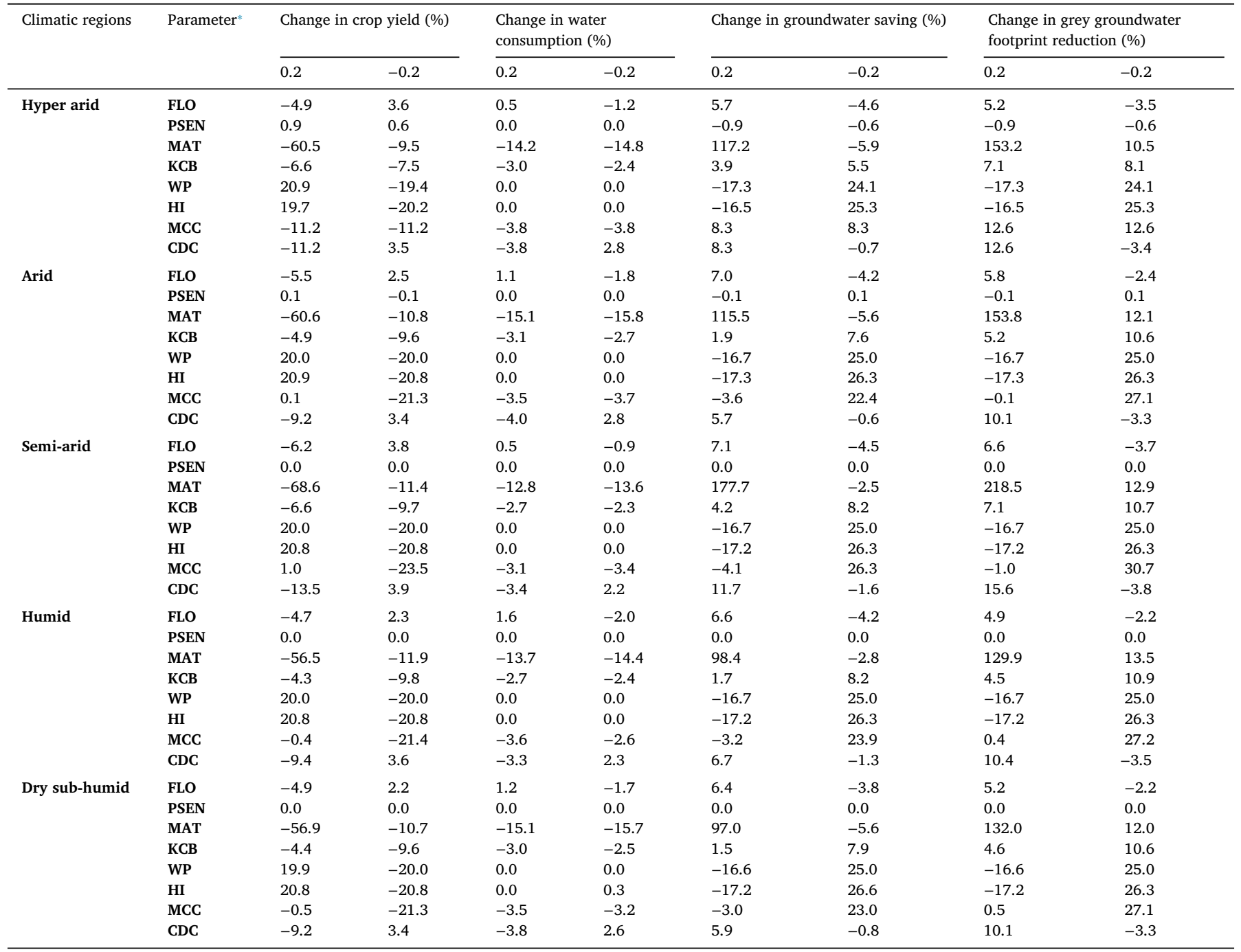

${ }^{*}$ FLO: growing degree days from sowing to flowering, PSEN: upper threshold of soil water depletion factor for canopy senescence, MAT: total length of crop cycle in growing degree-days, KCB: crop coefficient when canopy is complete but prior to senescence, WP: normalized water productivity, HI: harvest index, MCC: maximum canopy cover in fraction soil cover, CDC: growing degree day decrease in canopy cover

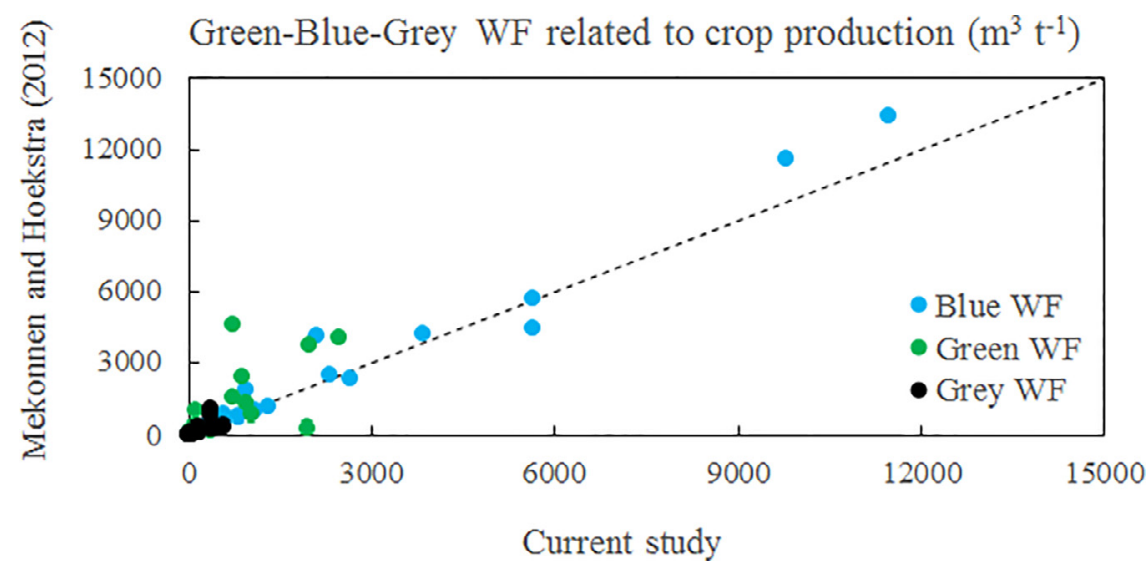

Fig. 7. Comparison of estimated green, blue and grey WFs related to crop production with results reported by Mekonnen and Hoekstra (2012). 
focused on a limited number of agricultural crops (Chukalla et al., 2015; Zhuo et al., 2016a), we considered a wide range of common agricultural and horticultural crops cultivated all over the world.

\section{Conclusion}

Groundwater plays a central role in Iran's irrigated agriculture. Of all blue water consumption in the period $1980-2010$, up to $83 \%$ was supplied by groundwater resources, with the highest contribution typically in the arid zones of the country. We found that Iran's groundwater resources are under severe stress in the hyper-arid, arid and semi-arid zones, and under significant stress in the humid zone (Table 3). Moreover, Iran's aquifers suffer from severe nitrate contamination within the semi-arid and humid zones. Our findings reveal that cereals, and especially wheat, make up the majority of groundwater consumption.

The results show that significant groundwater savings and groundwater pollution reduction can be achieved when farmers would reduce total blue WFs and grey GWFs of crop production to certain reasonable benchmark levels. If WFs of the considered 26 crops had been reduced to benchmark levels as defined by the 25th best production percentile, groundwater consumption in Iran's crop production would have been 3.2 billion $\mathrm{m}^{3} \mathrm{y}^{-1}$ less than the actual groundwater consumption in 1980 and 9.3 billion $\mathrm{m}^{3} \mathrm{y}^{-1}$ less in 2010. Although we expect them to be relatively small, other groundwater consuming activities not considered in this study (e.g. minor crops) may aggravate our conservative groundwater scarcity estimates. Reducing WFs to 25th percentile benchmark levels would have resulted in groundwater savings between $30 \%$ and $34 \%$ over the period $1980-2010$. Grey GWF reduction would have been 0.7 billion $\mathrm{m}^{3} \mathrm{y}^{-1}$ in 1980 and 1.9 billion $\mathrm{m}^{3} \mathrm{y}^{-1}$ in 2010 . Over the period 1980-2010, grey GWF reduction as a fraction of the total grey WF would have varied between $22 \%$ and $24 \%$. The highest priority should be given to cereal production in the arid zone.

With this study, we provide a narrative for how to use WFs and benchmarking of WFs to assess potential water savings, potential water pollution reduction, and possible economic water productivity increase. Although we took Iran as a case and its aquifers as an example, we believe the methods put forth in this study can be applied to other regions and surface water resources as well. This research may serve as a next step towards actual uptake of WF benchmarking into national water policy.

\section{Acknowledgement}

Fatemeh Karandish would like to thank the University of Zabol for financing the project (Grant Number: UOZ_GR_9517_6).

\section{Supplementary materials}

Supplementary material associated with this article can be found, in the online version, at doi:10.1016/j.advwatres.2018.09.011.

\section{References}

Aldaya, M.M., Garrido, A., Llamas, M.R., Varelo-Ortega, C., Novo, P., 2010. Water footprint and virtual water trade in Spain. In: Garrido, A, Llamas, MR (Eds.), Water Policy in Spain. CRC Press, Leiden, pp. 49-59.

Allen, R.G., Pereira, L.S., Raes, D., Smith, M., 1998. Crop Evapotranspiration Guidelines For Computing Crop Water requirements-FAO Irrigation and Drainage Paper 56, 300. FAO, Rome 1998.

Batjes, N.H., 2012. ISRIC-WISE Global Data Set of Derived Soil Properties on a 5 by 5 Arc-minutes Grid (Version 1.2). Report 2012/01. ISRIC World Soil Information, Wageningen, the Netherlands.

Bouwer, H, 1977. Land subsidence and cracking due to ground-water depletion. Groundwater $15,358-364$.

Brauman, K.A., Siebert, S., Foley, J.A., 2013. Improvements in crop water productivity increase water sustainability and food security: a global analysis. Environ. Res. Lett. $8024030,2013$.

Chukalla, A.D., Krol, M.S., Hoekstra, A.Y., 2015. Green and blue water footprint reduction in irrigated agriculture: effect of irrigation techniques, irrigation strategies and mulching. Hydrol. Earth Syst. Sci. 19 (12), 4877-4891.
Chukalla, A.D., Krol, M.S., Hoekstra, A.Y., 2017. Marginal cost curves for water footprint reduction in irrigated agriculture: guiding a cost-effective reduction of crop water consumption to a permit or benchmark level. Hydrol. Earth Syst. Sci. 21, 3507-3524.

Chukalla, A.D., Krol, M.S., Hoekstra, A.Y., 2018. Grey water footprint reduction in irrigated crop production: effect of nitrogen application rate, nitrogen form, tillage practice and irrigation strategy. Hydrol. Earth Syst. Sci. 22 (6), 3245-3259.

Dalin, C., Wada, Y., Kastner, T., Puma, M.J., 2017. Groundwater depletion embedded in international food trade. Nature 543, 700-704.

FAO, 2017. FAOSTAT. Food and Agriculture Organization, Rome, Ital.

FAO, 2016. AQUASTAT. Food and Agriculture Organization, Rome, Italy http://www.fao.org/nr/water/aquastat/main/index.stm.

Franke, N., Boyacioglu, H., Hoekstra, A., 2013. Value of Water Research Report Series No. 65. UNESCO-IHE, Delft, the Netherlands.

Ghale, Y.A.G., Baykara, M., Unal, A., 2017. Analysis of decadal land cover changes and salinization in Urmia Lake Basin using remote sensing techniques. Nat. Hazards Earth Syst. Sci. Discuss. https://doi.org/10.5194/nhess-2017-212.

Hoekstra, A.Y., 2013. The Water Footprint of Modern Consumer Society. Routledge, London, UK.

Hoekstra, A.Y., 2014. Sustainable, efficient, and equitable water use: the three pillars under wise freshwater allocation. Wiley Interdiscip. Rev. 1, 31-40.

Hoekstra, A.Y., Chapagain, A.K., Aldaya, M.M., Mekonnen, M.M., 2011. The Water Footprint Assessment Manual: Setting the Global Standard. Earthscan, London, UK.

Hoekstra, A.Y., Mekonnen, M.M., 2012. The water footprint of humanity. Proc. Natl. Acad. Sci. 109 (9), 3232-3237.

Hoekstra, A.Y., Mekonnen, M.M., Chapagain, A.K., Mathews, R.E., Richter, B.D., 2012 Global monthly water scarcity: blue water footprints versus blue water availability. PLoS ONE 7 (2), e32688.

Hogeboom, R.J., Hoekstra, A.Y., 2017. Water and land footprints and economic productivity as factors in local crop choice: the case of silk in Malawi. Water 9 (10), 802.

Hui-Min, X., Xin-gang, X., Zhen-hai, L., Yi-jin, C., Hai-kuan, C., Gui-jun, Y., Zhao-xia, C. 2017. Global sensitivity analysis of the AquaCrop model for winter wheat under different water treatments based on the extended Fourier amplitude sensitivity test.

Hsiao, T.C., Heng, L., Steduto, P., Rojas-Lara, B., Raes, D., Fereres, E., 2009. AquaCrop-the FAO crop model to simulate yield response to water: III. Parameterization and testing for maize. Agron J. 101, 448-459.

IRIMO, 2016. Iran Meteorological Organization, Tehran, Iran. www.irimo.ir/far.

IMAJ 2016 Iran's Ministry of Agriculture Jihad www.maj.ir.

Karandish, F., Darzi-Naftchali, A., Asgari, A., 2017a. Application of machine-learning models for diagnosing health hazard of nitrate toxicity in shallow aquifers. Paddy Water Environ. 15 (1), 201-215.

Karandish, F., Hoekstra, A.Y., 2017. Informing national food and water security policy through water footprint assessment: The case of Iran. Water 9 (11), 831.

Karandish, F., Mousavi, S.S., 2016. Climate change uncertainty and risk assessment in Iran during twenty-first century: evapotranspiration and green water deficit analysis. Theoretical Appl. Climatol. 1-15.

Karandish, F., Mousavi, S.S., Tabari, H., 2017b. Climate change impact on precipitation and cardinal temperatures in different climatic zones in Iran: analyzing the probable effects on cereal water-use efficiency. Stoch. Environ. Res. Risk Assess. https://doi.org/10.1007/s00477-016-1355-y.

Karandish, F., Šimůnek, J., 2018. An application of the water footprint assessment to optimize production of crops irrigated with saline water: A scenario assessment with HYDRUS. Agric. Water. Manage. 208, 67-82.

Konikow, L.F., Kendy, E., 2005. Groundwater depletion: a global problem. Hydrogeol. J. 13, 317-320.

Madani, K., 2014. Water management in Iran: what is causing the looming crisis? J. Environ. Stud. Sci. 4 (4), 315-328.

Marston, L., Konar, M., Cai, X., Troy, T., 2015. Virtual groundwater transfers from overexploited aquifers in the United States. Proc. Natl. Acad. Sci. 112 (28), 8561-8566.

Mekonnen, M.M., Hoekstra, A.Y., 2011. The green, blue and grey water footprint of crops and derived crop products. Hydrol. Earth Syst. Sci. 15 (5), 1577-1600.

Mekonnen, M.M., Hoekstra, A.Y., 2014. Water footprint benchmarks for crop production: a first global assessment. Ecol. Indic. 46, 214-223.

Mekonnen, M.M., Hoekstra, A.Y., 2016. Four billion people facing severe water scarcity. Sci. Adv. 2 (2), e1500323.

Mekonnen, M.M., Hoekstra, A.Y., Becht, R., 2012. Mitigating the water footprint of export cut flowers from the Lake Naivasha Basin, Kenya. Water Resour. Manage. 26, 3725-3742.

Monteny, G.J., 2001. The EU Nitrates directive: a European approach to combat water pollution from agriculture. Scientific World J. 1, 927-935.

Naeem, S., et al., 2015. Environment and development. Get the science right when paying for nature's services. Science 347 (6227), 1206-1207.

Qureshi, M.E., Reeson, A., Reinelt, P., Brozovic, N., Whitten, S., 2012. Factors determining the economic value of groundwater. Hydrogeol. J. 20 (5), 821-829.

Raes, D., Steduto, P., Hsiao, T.C., Fereres, E., 2009. AquaCrop-The FAO crop model to simulate yield response to water: II. Main algorithms and software description. Agron J. 101, 438-447. https://doi.org/10.2134/agronj2008.0140s, 2009.

Rahnema, H., Mirassi, S., 2014. Crisis management concerning underground water falling and land subsidence occurrence in the plains of Iran. Adv. Environ. Biol. 8 (5), 1453-1465.

Schyns, J.F., Hoekstra, A.Y., 2014. The added value of water footprint assessment for national water policy: a case study for Morocco. PLOS ONE 9 (6), e99705.

Schyns, J.F., Hoekstra, A.Y., Booij, M.J., 2015. Review and classification of indicators of green water availability and scarcity. Hydrol. Earth Syst. Sci. 19, 4581-4608.

Siebert, S., Doll, P., 2010. Quantifying blue and green virtual water contents in global crop production as well as potential production losses without irrigation. J. Hydrol. 384, 198-217. 
Siebert, S., Henrich, V., Frenken, K., Burke, J., 2013. Update of the global map of irrigation areas to version 5. University of Bonn/FAO, Bonn, Germany / Rome, Italy, p. 178. https://doi.org/10.13140/2.1.2660.6728.

Steduto, P., Hsiao, T.C., Raes, D., Fereres, E., 2009. AquaCrop-The FAO crop model to simulate yield response to water: I. Concepts and underlying principles. Agron. J. $101,426-437$.

Wada, Y., van Beek, L.P.H., Bierkens, M.F.P., 2012. Nonsustainable groundwater sustaining irrigation: a global assessment. Water Resour. Res. 48 (6) W00L06.

WRM 2016. Iran water resources management company http://www.wrm.ir/.

Zhuo, L., Mekonnen, M.M., Hoekstra, A.Y., 2014. Sensitivity and uncertainty in crop water footprint accounting: a case study for the Yellow River Basin. Hydrol. Earth Syst. Sc. 18 (6), 2219-2234.
Zhuo, L., Mekonnen, M.M., Hoekstra, A.Y., Wada, Y., 2016a. Inter- and intra-annual variation of water footprint of crops and blue water scarcity in the Yellow River Basin (1961-2009). Adv. Water Resour. 87, 21-41.

Zhuo, L., Mekonnen, M.M., Hoekstra, A.Y., 2016b. Benchmark levels for the consumptive water footprint of crop production for different environmental conditions: a case study for winter wheat in China. Hydrol. Earth Syst. Sci. 20 (11), 4547-4559.

Zwart, S.J., Bastiaanssen, W.G.M., de Fraiture, C., Molden, D.J., 2010. A global benchmark map of water productivity for rainfed and irrigated wheat. Agric. Water Manage. 97, 1617-1627. 